\title{
Belonging across the lifetime: Time and self in Mass Observation accounts
}

DOI:

10.1111/1468-4446.12276

\section{Document Version}

Accepted author manuscript

Link to publication record in Manchester Research Explorer

\section{Citation for published version (APA):}

May, V. (2017). Belonging across the lifetime: Time and self in Mass Observation accounts. British Journal of Sociology, 69(2), 306-322. https://doi.org/10.1111/1468-4446.12276

\section{Published in:}

British Journal of Sociology

\section{Citing this paper}

Please note that where the full-text provided on Manchester Research Explorer is the Author Accepted Manuscript or Proof version this may differ from the final Published version. If citing, it is advised that you check and use the publisher's definitive version.

\section{General rights}

Copyright and moral rights for the publications made accessible in the Research Explorer are retained by the authors and/or other copyright owners and it is a condition of accessing publications that users recognise and abide by the legal requirements associated with these rights.

\section{Takedown policy}

If you believe that this document breaches copyright please refer to the University of Manchester's Takedown Procedures [http://man.ac.uk/04Y6Bo] or contact uml.scholarlycommunications@manchester.ac.uk providing relevant details, so we can investigate your claim.

\section{OPEN ACCESS}




\author{
Belonging across the lifetime: Time and self in Mass Observation accounts \\ Vanessa May \\ Morgan Centre for the Study of Everyday Lives \\ Sociology \\ University of Manchester \\ Oxford Road \\ Manchester M13 9PL \\ United Kingdom
}

\begin{abstract}
Our sense of belonging rarely stands still, yet the research literature has hitherto paid little attention to the temporal nature of belonging. Based on an analysis of 62 Mass Observation Project (MOP) accounts written by people living in the UK aged from their 20 s to their 90 s, this paper argues that as people age, how they locate belonging in time shifts. This has to do with changing concerns related to belonging, but also to metaphysical issues of temporal ity and mortality, namely how people experience their own finite lifetime. The paper thus offers an illustrative example of how time can be empirically researched in sociology, with a particular focus on the important role that the future plays in how people construct their 'functional present' (Mead, 1932). The central argument put forward is that time itself can be an important source of belonging, but one that is unequally accessible to people of different ages because of contemporary cultural scripts that present life as a linear progression into the future and construct the future as a more meaningful temporal horizon than the past.
\end{abstract}

Key words: belonging, time, narrative, self, ageing, Mass Observation

\title{
Introduction
}


Our sense of belonging rarely stands still, yet the research literature has hitherto paid little attention to the temporality of belonging. People's experiences of belonging - defined as a sense of ease with oneself and one's surroundings that is fundamental to our sense of self (May 2013) - though understood to be dynamic, tend to be researched from the perspective of place, particularly in the context of social change or geographical mobility (e.g. Fortier 2000; Bönisch-Brednich and Trundle 2010; Passerini et al. 2007; Savage et al. 2005). The aim of the present paper is to add to our understanding of the temporal nature of belonging by analysing 62 Mass Observation Project (MOP) accounts written by people living in the UK aged from their 20s to their 90s. The Mass Observation Project is comprised of a panel of volunteer writers who three times a year are sent a directive that invites them to engage with a particular topic, ranging from current events to everyday subject matters such as relationships and technology. In 2010 I commissioned a directive that enquired about Mass Observers' experiences of belonging and not belonging. The focus of the analysis lies on how the MOP writers of different ages make sense of belonging as a temporal phenomenon, and on how ageing impacts their ability to build a sense of belonging in time. While much of the literature on old age depicts it as a time of reminiscence and nostalgia (Segal 2013), the present paperaims to complicate such interpretations by arguing that as people age, how they locate belonging in time shifts. This has to do with changing concerns, but also more metaphysical issues of temporality and mortality, namely how people experience their own finite lifetime. I have chosen to utilise the term 'lifetime' instead of 'life-course' in order to highlight that the focus of the analysis is time itself, not the different stages of a life-course. In addition, whereas the concept of life-course presents human life as linear, the MOP writers adopt cyclical or spiral temporalities to make sense of their lives.

The following section explores relevant work on narrative identity understood as necessarily temporal (and mortal), followed by a description of the data and methods of data analysis. The paper then proceeds to present the analysis of the MOP accounts divided into three age groups, each with a different emphasis on belonging as a temporal experience. I conclude with a discussion of the contribution that this paper offers to the literature on belonging as well as the literature on 
temporal narrative selves, particularly concerning ageing. The central argument put forward is that time itself is an important source of belonging, but one that is unequally accessible to people of different ages because of contemporary cultural scripts that present life as a linear progression into the future and construct the future as a more meaningful temporal horizon than the past. The broader significance of this paper hinges on offering a better understanding of a key topic of interest for sociologists, namely the self, and more specifically, the temporal nature of the self.

\section{Temporal (mortal) narrative selves}

As noted by probably every scholar who has written about the topic, time is both ubiquitous and hard to pin down: although all aspects of human lives are temporal, time itselfremains an elusive phenomenon without physical tangibility. Each person exists as 'a temporal field that embraces past and future' such that our experience of 'now' is not 'the pinpoint of a lived present devoid of history', but rather 'the rich but complicated time of initiative wherein we acknowledge the past and anticipate the future' (Schatzki 2010: 166; Muldoon 2006: 62-3, 87-8). The temporal boundaries of our experience of this 'duration' (Bergson 1988) or 'functional present' (Mead 1932: 88) are determined by the activity we are engaged in. The present becomes 'a "field of attention" that can be made shorter or longer' (Muldoon 2006: 83) and from which we actively construct our past and future horizons as we consider 'what just happened, what is happening right now and what is expected to happen next' (Baars 1997: 290). In otherwords, in order to make sense of the passage of time, we construct narratives that give time a human dimension (Ricoeur 1984; Muldoon 2006).

Narratives are also 'a necessary condition' for the self that is constructed through an ongoing reflexive autobiographical practice (Brockmeier 2000: 53, 54) whereby we tell stories about who we have been, who we are, and who we hope to be or are afraid of becoming. Quoting Kierkegaard, Brockmeier (2000:52, 54) observes that a human life must be understood backwards, 
by evaluating the present self in light of past events, but is always lived forwards into the future, leading to 'a back-and-forth movement between the past and the present that furthe rmore relates to the future'. Luhmann (1976) proposes that the past and the future must be conceived of as time horizons of the present that contribute to how we define our present. This means that 'every narrative about my past is always also a story told in, and about, the present as well as a story about the future' (Brockmeier 2000: 56). The past is the past of this present in that the past events that endure are not simply things that have happened to us that survive in our memory but ones that we still re-experience as 'non-linear durations' (Coleman 2008: 93), such as the effect of hurtful words that still ring in our ears. Similarly, a person's future is not one of infinite possibilities, but is 'limited or conditioned' by what a person has been through that endures (Coleman 2008: 97). The importance of the future has been heightened by 'the individualization of a personal regard for the future' which entails that contemporary Western individuals must adopt reflexive awareness and calculative strategies in order to safeguard their own futures (Binkley 2009: 95).

Thus, people's future horizons are important exactly because these inform how they perceive and act in the present (Uprichard 2011). Apart from research on young people concerned with life-course transitions (e.g., Phoenix and Sparkes 2008; Brannen and Nilsen 2005; Carmo et al. 2014), studies focusing on temporal selves, especially ageing selves, have not been that interested in the future. Similarly, the belonging literature is for the most part oriented towards the present and the past with a focus on how people re-gain (or not) a sense of belonging once it has been unsettled or lost (e.g., Bönisch-Brednich and Trundle 2010; Passerini et al. 2007). I will come to argue that a focus on future horizons is important, particularly in light of mortality, because the anticipated future influences how a person orients themselves temporally in terms of belonging.

The analysis reveals how the MOP writers' concerns regarding belonging shift as they age, influenced, I argue, by their increasing awareness of their own mortality and by cultural scripts which are 'amputated' at middle age (Spector-Mersel 2006). With reference to Heidegger's work, 
Schatzki (2010: 166) states that 'the two end points, birth and death, are ipso facto connected whenever Dasein exists ... because existence is a self-stretching out that encompasses beginning and end'. Our experience of time and our awareness of the mortality of our bodies are thus inextricably linked: when we make time human, 'time's passage becomes the recognizable birth, life, and death of someone' (Muldoon 2006: 177, 195). Many of us also know approximately how long the average lifespan in our society is - currently around 80 years in the UK (ONS 2014) - and use this to assess 'how much time is behind us and how much time we are left with', which in turn colours how we 'interpret our past and plan our future' (Spector-Mersel 2006: 70). But in addition, the meanings we attach to our lifetime are cultural. In Western cultures, a human lifespan is understood to progress through stages including childhood, adolescence, middle age and old age. There exists a prescriptive timetable for major life events such as marriage and having children, and people are generally aware of how their own lives measure against the se various social clocks as either 'on time', 'early' or 'late' (Neugarten et al. 1965). Brockmeier (2000: 70) conceptualises such cultural scripts as 'cultural moorings of individual identity construction' that act as 'dialectical hinges between individual and society', helping individuals 'to re-invent the culture in their minds', while also binding the individual into culture. The present paper offers a critique of such normative social clocks which, in the case of illness and old age, can act to limit a person's ability to build a sense of belonging in time.

\section{Methods}

The written accounts analysed in this paper derive from the Mass Observation Project (MOP) housed at the University of Sussex. The Project, which in its current form has been ongoing since 1981, involves a panel of volunteer writers, known as Mass Observers - around 500 at any one time from around the UK - who three times a year receive a directive to write about specific topics. When new members are required on the panel, volunteer writers are sought by the Project through open calls, for example in newspapers or on radio. The panel is not nationally representative, though in 
recruiting new members, the Project does aim 'to maintain a broad and diverse cross-section of “ordinary people"' (Bytheway, 2005: 467), which includes trying to attract writers from groups that are under-represented on the panel, including men, younger people, and people from ethnic minority backgrounds. In 2010, I commissioned a directive on belonging - designed in collaboration with staff at Mass Observation - that asked Mass Observers to consider what (not) belonging meant to them, how their experience of belonging might have changed during their lifetime, and to provide examples of particular times or settings where they had felt a sense of (not) belonging.

Commissioning the directive had two central aims: first, to create a dataset that allowed for the exploration of the complexity of belonging as a multidimensional experience that can encompass different sources of belonging, as well as simultaneous experiences of belonging and not belonging (May 2011), and second, to offer people the space and time to think about and develop their thoughts on a topic that is rather abstract and therefore can be difficult to investigate through interviews (May and Muir 2015).

In addition to the usual writing task, Mass Observers were asked to draw a relational diagram depicting the people they felt a sense of belonging to at the time of writing and another for ten years ago, and to list all the places or settings where they felt at home at the time of writing and ten years ago, and to comment on what might have changed and why. The MOP writers were thus 'primed' in various ways by the directive to think about time and change, and to reflect on belonging across the lifetime. This is not unlike what happens in a qualitative research interview, where the researcher's questions guide the direction of the conversation. But, as I have noted elsewhere, when collecting written data, research participants are perhaps freer in terms of how they construct their narratives because the researcher's interaction with the $m$ is restricted to the initial guidance on the kinds of account that are sought (May 2008).

The belonging directive gained responses from $185 \mathrm{MOP}$ writers. This paperfocuses on a subsample of 62 of these accounts that were chosen because they explicitly address the issue of 
time by telling configurational narratives that overtly talk about belonging in light of the passage of time and use an autobiographical discourse of interpretation that interprets 'the facts' of the narrative, giving them wider significance in the context of the writer's lifetime (Muldoon 2006; Bruner, 1995: 167). These configurational narratives collect disparate events around a theme or plot (Muldoon, 2006: 191-3), often inverting the 'natural order of time' by offering flashes forward and backward. Forty-four of these accounts were written by women and 18 by men. The youngest writer is 20 and the oldest 91 (median age 52, average age 55). Because the gender balance, age spread and average age of the sub-sample reflect that of the whole dataset, I cannot draw any conclusions as to who might be more or less inclined to write about the temporal aspects of belonging. I assume that all 62 writers are white because most Mass Observers are white British (Black and Crann 2002), but also because none of them mention their ethnicity - the majority ethnic group have this privilege of not noticing their ethnicity because it is unremarkable (e.g. Byrne 2006). Similarly with sexuality: two of the writers say that they are gay men, while the rest do not explicitly mention their sexuality (and most of them write about opposite-sexpartners) and are therefore presumed to be straight. The majority $(\mathrm{N}=49)$ work in or are retired from white-collar occupations ranging from teacher's assistant to consultant, three have (had) blue-collar occupations, two are students, one is a housewife, two are off work due to long-term illness and four of the writers do not indicate their (former) occupation. Comparing the length of the accounts is difficult because some were handwritten, others typewritten, with different margins, line spacing and fonts or styles of handwriting, but as such, the accounts varied in length between one and seven pages.

The analysis of these 62 accounts proceeded by focusing on the 'temporal orientation' of each account, made up of shadows of time, time tense, and temporal order, each briefly described below. The MOP accounts are narratives about experiences of belonging from the perspective of the writer's present, onto which backshadows, foreshadows and sideshadows can be cast (Morson 1984). When backshadowing, a narrator portrays the present as an unavoidable result of the past, while foreshadowing means bringing anticipated future events that have not yet happened into the 
present, the consequence of which is 'that the present becomes a preparation for a hypothetical future' (Pedersen 2009: 393). Sideshadowing, on the other hand, where we contemplate the paths that we chose not to take, means that possible alternative avenues become part of the story (Pedersen 2009), conveying 'the sense that ... what exists need not have existed' (Morson 1994: 699). Another way of conceptualising the relation between past, present and future is 'time tense', which refers to whether events are interpreted through the past, present or future; the future can be read through the past, or the present can be interpreted through the future, and so on (Roberts 2004). In doing so, narrators 'telescope' time, weaving 'several structures of events, each representing a distinct temporal level' into 'a texture of sometimes incredible density' (Brockmeier 1995: 114). As a result, different temporal orders, including linear/elliptical, direct/reverse, or continuous/discontinuous, can be absorbed into one narrative.

For each writer I noted the following: the use of temporal shadowing, time tense, and the temporal orders created. The accounts were grouped together in decennial age groups and the analysis focused on whether there were similarities within and between these in terms of the writers' temporal orientation. There are indeed some quite distinct characteristics that the younger writers in their 20s and 30s share in terms of how they narrate belonging as a continuously changing and future-oriented experience, due to changes in the self. For these writers, cultural narratives that prescribe how the life-course 'should' proceed offer a sense of belonging, something that is pal pably missing in the accounts of those writers who have been knocked off cou rse by illness. Mass Observers in their 40s, 50s and 60s can reflect back on decades of adult life and contemplate how belonging can have varying degrees of permanence, while the older writers aged 70 and older have concerns relating to loss that are not visible in the accounts of the younger writers. The analysis will also critically consider the role that 'amputated' cultural scripts play in the accounts of the older writers. There were no marked differences in how women and men within these age groups discussed belonging. Below, I discuss the results of the analysis for each of these three groups in more detail. 


\section{Turmoil and change}

The writers in their 20s and 30s $(\mathrm{N}=10)$ are concerned with the changes that their sense of belonging is or has been undergoing as they transition to adulthood. In these accounts, the future looms large. Such constant change can lead to belonging being experienced as temporary: 'I have learnt that belonging can be a very transient thing and as such I don't put too much faith in a sense of belonging as I am al ways expecting the situation to change' (B4458, F31, University administrator ${ }^{1}$ ). These are accounts about change and turmoil, telling of key life-course transitions-such as leaving the parental home, going to university, getting a job, finding a partner and having children -that have led to an evolving sense of belonging. The emphasis is often on belonging (Probyn 1996), on striving for and seeking a sense of belonging. In the midst of major life transitions, it can feel as though it is the self rather than the world that is changing:

I felt very much part of things at University. However, I remember going back a few months after I left for a visit. I sat in the refectory and became acutely aware that I need not belong there anymore. I feel everything was the same expect me. I think it was because simply, my time there had passed. Life moves on. ...I think this is a natural process and the way our lives continue to evolve. (R4518, F38, learner support)

In talking of such change as being 'a natural process', the writer above is drawing from sociocultural scripts to make sense of her life. According to these (classed) scripts, a person's twenties and thirties 'should' be a time of transition (Phoenix and Sparkes 2008), a sentiment that is reflected also in the otheraccounts:

My sense of belonging has dramatically and quite continually changed over the last few years as I've been establishing myself in London, in a career, in 3 different relationships. I think this would be the same for most people while they're in their twenties; before they 
'settle down' - though I hate the term, I guess it signifies sense of knowing where you belong. (C3210, F20s)

The writer above indicates not only that 'settling down' entails achieving a more stable sense of belonging, but also that there is a 'proper' time for 'growing up' (Phoenix and Sparkes 2008). Measured against such social clocks, the majority of the younger MOP writers seem to feel they are 'on time' (Neugarten et al. 1965). These cultural narratives orient the younger MOP writers' temporal focus toward a particular kind of future (a middle-class future of career and home ownership), and the present is read through this anticipated future. The 'arrow of time' moves from past to future in a relatively linear fashion in these accounts, and there is next to no sideshadowing, little sense of a life that could have been different. In his study of Norwegian young people's narratives, Øian (2004) notes the vital role that linear time plays in how they construct their selfidentities as future-oriented and in terms of a unidirectional personal career of development during which different forms of social and cultural capital are accumulated. Phoenix and Sparkes (2008: 220) express concern that the apparent fixity of such cultural scripts about 'settling down' can curtail young people's horizons of possibility. Thus, while the younger MOP writers are focused on constant change in the present, they might paradoxically view their future as a foregone conclusion, perhaps in the process setting themselves up for future disappointment if their lives do not follow the expected path (Pedersen 2009; Phoenix and Sparkes 2008). The effects of such narrative foreclosure (Morson 1994) can be interrogated by comparing these accounts written by young adults who seem to be 'on time' in relation to social clocks with accounts written by people of a similar age, or slightly older, who talk about being knocked off course by illness.

\section{A life derailed}


There are four accounts where illness has 'derailed' the writer such that they feel they are 'off time'. Sideshadowing is strongly present as all four read their past and present through a life that they have not been able to live. The first writer recounts the severe impact that his congenital illness has had throughout his life, being unable to 'do many of the more energetic pastimes that my contemporaries amused themselves with', which contributed to a deep sense of being out of step with and isolated from his peers: 'At the very time that I should have been forming bonds and learning social skills, I had no-one to talk to, no-one to relate to' (F4395, M47, marketing, communications and sales support officer, emphasis added). This sense of being temporally off kilter compared to his contemporaries has continued into adulthood, as the writer's relationships with his work friends have grown more distant because they 'are all now either settled with partners, or with partners and children, so I feel less of a sense of belonging with them, as their domestic set-up is so very different from my own'.

The remaining three writers describe their experience of temporal derailment in more detail, perhaps because, after a period of 'normal life' (as two of the writers call it), the impact of illness is marked and sudden. A woman in her late 20s (B4527, F29, teacher no longer working due to illness, but studying at the Open University), describes feeling 'removed from my friends, \& from my peers', no longer belonging 'in their world'. In comparison to 'other people my age who are getting married, having children, progressing in their careers, getting mortgages etc', the writer is 'living on benefits, only able to afford a single room' and spending much of her time in hospital. The second writer, a woman in her40s (A2801, F44, previously trainee solicitor but unable to work due to illness), expresses a sense of yearning towards a life not lived. She tells of how 'unbearable' it is for her 'to not belong to the life I envisaged for myself', which included having a career, living in a 'comfortable detached house', getting married and having children. Instead, she lives in a 'council bungalow' in an environment populated by 'frail, older people', something that she finds 'depressing'. The writer says that she feels 'apart from things, on the outside, peripheral, separate, alienated, and looking on to something I couldn't be a part of', namely 'well society', 'normal life', 
and her 'peer group who finished university and have gone on to careers, marriages, divorces, children and social lives'. Similarly, the third writer, a man in his 40s (B3968, M44, community health worker currently not in paid employment due to ill health), describes how his illness has derailed him from the 'normal' life he had built with his partner, leaving him isolated, feeling as though 'the world is going by without me.'

These are not the chaos narratives often told by people suffering from severe illnesses characterised by a plot where life is not expected to get any better and that are chaotic in their lack of narrative order and causality (Frank 1995; Sparkes and Smith 2003). This is perhaps because the very format of autobiographical writing requires some coherence, in addition to which, it is rare for written self-narratives to end on a negative note (May 2001). Nevertheless, the static temporal order of these accounts does convey a sense of being stuck in a time not of one's own choosing (Brockmeier 2000). Illness can denote a loss of temporality and a sense of time running away 'because its present is not what the past was supposed to lead up to' (Frank 1995: 55) and because one is not able to 'make the time move by one's own cumulative actions', which in turn is seen to signify 'a lack of individual autonomyand vigour' ( Øian 2004: 187). The consequence is a sense of falling off the stream of the life-course seen as a 'linear cumulating of a career into the future' ( $\varnothing$ ian 2004: 188). These accounts serve to highlight that social clocks can offer a sense of belonging, though this might not be consciously thought of until one finds oneself 'off time' and unable to achieve this form of belonging in the world.

\section{Reflection and comparison}

We now return to accounts written by people in their $40 \mathrm{~s}, 50 \mathrm{~s}$ and $60 \mathrm{~s}(\mathrm{~N}=28)$ who indicate a sense of being 'on time' in relation to social clocks. These writers have at least two decades of adulthood behind them and can look back on and compare different phases within their adult lives, as 
illustrated by the following two writers whose take on 'settling down' differs somewhat. The first writer, a man in his 40s, wistfully comments that his relationships with his friends have become less intense in the last ten years because 'life has changed, we've moved some distance from each other, some have got married and had children' (S4070, M44, paediatric nurse). The second writer, a woman also in her 40s, notes how her preferences have changed since her 20s when she enjoyed living amidst the 'noise, faster pace of life, movement, buildings' of a city (W3730, F43, Citizens Advice Bureau desk worker). In contrast to the first writer who seems to regret the fixity that settling down has entailed for him, the second writer embraces life in the small market town that she has moved to. Nevertheless, in both accounts, there is a sense of there being a 'proper' time for the pace of life to calm down: 'maybe as we get older we don't have the energy for that level of intensity? (\$4070).

The two accounts above also illustrate how constant change remains a theme, though compared to the younger writers, the narrators in the middle of their (expected) lifespan spend more time reflecting back in time. They identify clear phases of belonging that have been (or are expected to be) brought about by changes related to different stages of the life-course. The past is the past of this present and the present is interpreted through particular aspects of the past (Coleman 2008). It is from this vantage point that the MOP writers can reflect on what has made them who they are today: 'Later on i can look back and see that this experience [her mother dying when the writer was young] shaped me and as an adult and i became fiercely independent as a result' (M3469, F47, lead officer, child protection). Similarly, the anticipated future is read through this present (Coleman 2008). Thus, for example, the following Mass Observer can foreshadow that her closest group of friends will'al ways be a part of each other's lives' des pite 'interferences from family and life events', because experience has so far shown that 'you just pick up from where you left off, probably because you have so much history together' (A1706, F64, artist/ward clerk). Indeed, foreshadowing, barely used by the writers in their 40s, makes a return in the accounts of the writers in their 50s and 60s, for whom certain anticipated life transitions are nearing, such as 
retirement or one day becoming a widow(er), which act to introduce biographical uncertainty, particularly around loss of health, loss of income and loss of relationships (Facchini and Rampazi 2009). It is particularly loss of relationships that concerns the MOP writers, perhaps because they feel buffered from loss of income by their relative affluence and because many have not yet encountered serious health problems that would affect their ability to maintain a sense of overall belonging. Speaking of her hermit-like tendencies, one writer says of her plan for her eventual widowhood: 'But I have a master plan for the time I am left on my own ... one which will involve contact with one person at least once a week, and is to do with sharing the garden' (K798, F59, housewife and writer). Thus even in the face of biographical uncertainty, the MOP writers maintain the individualistic notion of being able to plan for the future (cf. Binkley 2009).

This middle group of writers begins to evaluate change in terms of which forms and sources of belonging are enduring and which have proven to be temporary and why (May 2016a). They tell of what growing maturity has taught them, such as seeking out 'the people I did belong with, people who accepted me as I was' (P3213, F44, housewife/mother/volcanologist), these experiences leading to greater 'confidence in my character' (R860, F63, retired). Some have realised that their sense of belonging has become less dependent on external circumstances, that 'you can continue to belong even when life changes' (S4070, M44, paediatric nurse). Thus fundamentally, although the 'natural course of events' is that places and networks of people are continually changing, "'belonging" still feels the same, more or less. The backdrop has changed' (M3190, M52, civil servant).

Whereas the temporal order in the accounts of the younger writers tended towards the linear, the accounts of this middle group are told in a spiral manner. There is more folding or telescoping of time such that the present is read through the past, while the future is to an extent read through the past and the present. The focus on continuities further emphasises the spiral nature of these accounts: while some things change, others endure, though perhaps in slightly altered form. This means that in contrast to the rather general notions of the future held by younger 
writers, these writers have a rather more concrete idea of what their future might hold. This future horizon begins to look quite different the older people get, as explored in the following section.

\section{Temporal displacement}

The contemporary Western cultural script, according to which old age is about becoming a 'reflective self' who looks back, not forward, in time (Phoenix and Sparkes 2008: 217; Segal 2013) is mirrored in the accounts of the oldest Mass Observers in their 70s, 80s and $90 \mathrm{~s}(\mathrm{~N}=20)$. As one writer notes 'Each decade alters your sense of belonging' (F1373, F78) before contemplating how her sources of belonging have shifted over time. Just like the middle group of writers, the older Mass Observers are concerned with continuity of belonging, but loss emerges as a new central theme. The oldest Mass Observers describe a gradually shrinking social world and 'a considerable loss of freedom' (M388, F79, former lecturer). Meeting up with friends can be hindered by 'difficulties of travel and mobility and self-imposed restraints' (R2143, M88, retired chartered engineer). Not being able to leave one's home leads to seeing 'fewer people' and thus losing circles 'where I used to have a feeling of belonging' (W2244, F81, married, retired teacher). It can also prove to be difficult to stay connected in other ways, for example phone conversations ' with those who are in denial about their deafness ... are fraught with misunderstanding' (M1395, F80, retired research chemist/CAB adviser). In comparison to the illness narratives told by the four younger writers in their 20 s and 40 s, these older writers seem to view debilitating illness as par for the course of ageing, as indicated by the last writer who speaks of the 'inevitability' of such developments. It is worth noting here that al most all of the oldest Mass Observers are middle-class people and thus more likely to have access to resources that protect them from the worst kinds of social exclusion faced by older people from more deprived backgrounds (cf. Buffel et al. 2013). 
The social world of the older writers is shrinking al so because their circle of friends is being thinned out by death: 'so many of those with whom I had strong, virtually lifelong, relationships have died' (R2143, M88, retired chartered engineer). In previous work, we concluded that those whose generation was dying out experienced a sense of losing their niche in contemporary society which can be experienced as 'temporal displacement', that is, 'a lessening of belonging to the broader social context', which in turn can translate into 'a nostal gic sense of belonging from afar to a time when they were deeply embedded in their "own" generation' (May and Muir 2015: 8.4). In contrast to the youngest group of writers, who were concerned with their changing selves, for the oldest Mass Observers it is the world, not just the self, that is changing. Migrating in time (Westerhof 2010) in this way can lead to a sense of being 'outmoded' in relation to contemporary society (Hyman 2014): 'living beyond the useful stage of life and believing in values no longer in vogue and therefore no longer counting for much. Having opinions perhaps with little relevance to what is going on around us' (R1418, M88, retired decorator).

In a situation where one's relational and cultural moorings are slowly becoming uncoupled, it is understandable that a sense of belonging is increasingly experienced in relation to memories (May 2016b). One writer notes how now that his friends are dying away, he is 'literally surrounded by mementos of their meaning for me; photographs, gifts, letters, picture postcards, and I am engulfed by memories' (R2143, M88, retired chartered engineer). Another writer reminisces happily about an open space 'fondly known to us as "the old rec"' where he used to play as a child that although dilapidated, has retained 'its memories and a welcoming air of belonging' (R1418, M88, retired decorator). Another writer comments that she has 'no interest in going back' to her old home town because 'I know the place has changed a lot, and I suppose I prefer to keep the good memories intact' (M388, F79, former lecturer).

Thus the oldest Mass Observers use the past somewhat differently from the young women in Coleman's (2008) study. The present does not pass through the past but is rather something the 
older Mass Observers seem to wish to get away from because both the present and the future are characterized by a sense of loss, combined with a sense of living in a world that is becoming increasingly foreign. Older people thus use reminiscing as a way of creating belonging in a 'pastsituated social identity' (Dowd 1986, quoted in Hyman 2014: 7.7). I suggest that in order to more fully understand why they do so, we must explore in more depth an existential point that Hyman (2014: 6.8) makes reference to only in passing, namely that they are 'closer to the ends of their lives', an experience that is culturally contingent, and in the case of the MOP writers, shaped by the lack of inspiring cultural scripts on ageing. Old age in Western cultures is presented in terms of decay and as a phase in life that is more about looking back to evaluate one's past life than it is about planning for the future (Facchini and Rampazi 2009). Older people are thus constructed as redundant to the point that Spector-Mersel (2006) talks of 'amputated' cultural scripts that stop at middle age.

We experience the future as an open screen onto which we project our hopes and fears, as 'a generalized horizon of surplus possibilities' that reduces with age, something that the oldest MOP writers are no doubt aware of (Luhmann 1976: 141, 143; see also Gell 1992; Muldoon 2006). As a consequence, ageing is likely to reduce a person's ability to engage with normative techniques of the self related to the dominant ideology in the West that emphasises the importance of future planning (Shirani and Henwood 2011; Øian 2004). In addition, the challenge of death has in contemporary Western cultures become particularly intense as a result of death being individualised and privatised (Mellor and Shilling 1993). Self-identity has become tied to the individual (mortal) body, while death is now the concern of the individual rather than the collective social body, further heightening people's anxieties surrounding their own ageing and death. It is perhaps not so much that as we age, we become inherently nostalgic, but that in the 'absence of clear cultural guidelines' (SpectorMersel 2006: 79) on how to be old and orient oneself towards the future, the oldest have nowhere but the past to go to in order to evaluate their present lives. De Medeiros (2005) raises the important question of to what extent the self-narratives that older people tell are merely reflections 
of cultural 'master narratives', and what might be left unsaid as a result of this.

\section{Conclusion}

This paper has been concerned with how people of different ages account for their experiences of belonging, further contributing to our theoretical understanding of temporal selves. Whereas the literature on temporal selves tends to posit a universal self that experiences time uniformly, the analysis of the MOP accounts has revealed different 'phases' in how people make sense of time in relation to belonging. These shifts are linked to the writers' awareness of time passing and of moving through culturally defined life stages ('settling down', 'middle age', 'old age'). It is however necessary to keep in mind the limitations of the findings presented here. The MOP writers were not specifically asked to consider the temporal nature of be longing, and therefore further research is necessary to explore in more depth the importance of time as a source of belonging, and the temporal nature of belonging. Furthermore, the MOP accounts analysed above are culturally situated accounts, pertaining to a mainly middle-class, white and heterosexual population living in the UK. Thus we have to be careful in drawing empirical conclusions to other populations. Further research is required to understand, for example, how being a member of an ethnic or sexual minority or experiencing severe deprivation influences shifts in belonging as people age, as well as to see if there are cross-national variations. Moreover, while it is impossible to say whether the differences found in the younger and older writers' accounts are the effects of age or cohort, I would argue that they are probably the result of both. It is in older age that people are more likely to face the kinds of situations that the older MOP writers describe (a shrinking world due to illness and death) and because one's own mortality is something that is likely to loom larger the older one becomes. But it is alsolikely that a different cohort of younger and older people would write about their experiences in different ways, partly due to the changes that occur in cultural scripts over time. 
In interpreting the MOP accounts, it is al so important to bear in mind that people tend to produce responses that they expect will be palatable to the listener (de Medeiros 2005: 9). As I have argued elsewhere (May 2008), when taking part in a writing project such as the Mass Observation Project, research participants do not have the same opportunities as interview participants do of gaging the response of the audience before they divulge non-normative aspects of the mselves, and might therefore stick to 'safer' ground. In addition, the MOP writers are aware that their accounts form part of an archive of everyday life, and may therefore feel the extra burden of sticking to culturally expected norms. These factors might explain why the MOP accounts quite neatly correspond with the cultural expectations of youth as future -oriented and old age as past-oriented. The question then remains of whether there are things that might be left unvoiced in these accounts that do not fit with cultural understandings of the different stages of a life, such as older people's dreams and fantasies for the future (de Medeiros 2005).

Nevertheless, this paper contributes a better understanding of the temporal nature of belonging. As the MOP accounts have shown, though people might not have a sense of belonging in the present perse, they can experience a sense of belonging from afar through the act of reminiscing, and may derive some pleasure from doing so (cf. Hyman 2014; May and Muir 2015; May 2016b). The paper also points to the important role that the future plays in people's sense of belonging. Even when not specifically asked about the future, how people understand their past and present lives, and belonging within it, is often infused with what they expect, hope or fearlies ahead of them. Though all of the Mass Observers to an extent anticipate the future and reflect back on their past, the balance shifts such that the 'anticipating self' of the younger writers who counts on or hopes for future belonging becomes the 'reflective self' of the oldest writers whose belonging is to an extent past-oriented (Phoenix and Sparkes 2008).

Crucially, the belonging literature has not paid sufficient attention to issues of lifetime and mortality, and how these might affect how people build a sense of belonging. I propose that the way 
the MOP writers build belonging in time is closely tied to their own mortality, where they find themselves on their expected lifespan, and how these are culturally delineated. The analysis of the MOP accounts indicates that as death comes ever closer, this places limits on narrative reflexivity. It could therefore be argued that as people age, their sense of belonging can become increasingly oriented towards their own mortality. What the MOP accounts also show is that belonging in time is culturally contingent. Western understandings of the self that are couched in terms of individualism and narratives of progression, where the self is expected to be 'productive' towards the future, have an important impact on how people can build a sense of belonging in time. Øian (2004: 185) notes that young people can use future-oriented self-narratives as a way of avoiding an 'imperfect present' that is 'filled with dilemmas and paradoxes', and indeed this is evident in the accounts of the youngest MOP writers. I argue that older people can use time in a similar way, but what they do instead is to turn their gaze back to the past, because their future horizon is curtailed in terms of available cultural narratives about ageing and death (Spector-Mersel 2006; Mellor and Shilling 1993). Much of the ageing literature depicts nostalgia as an inherent part of ageing (Segal, 2013). What I argue instead is that an orientation towards the past can be used as a technique to enliven the present, to offer oneself a temporal horizon, and to symbolically reverse time in the face of limiting cultural narratives.

In sum, time itself can be an important source of belonging, but one that people of different ages have unequal access to, and one that is difficult to attain if one has 'fallen off' the linear stream of the forward-moving life-course, either because of illness or old age. The analysis has however also demonstrated that people can utilise creative techniques to create a sense of belonging in time, either by utilising the past or the future as the context for realising the present ( $\varnothing$ ian 2004: 186). This paper thus offers a critique of normative future-oriented narratives of the self that present old age as a pinpoint with a diminishing temporal horizon, and of the cultural emphasis on the future horizon as more meaningful than the past. These issues of self, ageing and death, and how 
experiences of these are cultural ly shaped and constrained, are fundamental ones that go to the core of sociology's attempt to understand human life in social context.

\section{Acknowledgments}

I wish to thank the Mass Observers who responded to the belonging directive for their wonderful insights into belonging. My thanks also go to Emma Uprichard for her supportive and helpful comments on an earlierversion of this paper and to the Trustees of the Mass Observation Archive, University of Sussex for permission to use quotations from the Mass Observation Project material.I am also grateful to the three anonymous reviewers for their hel pful suggestions on how to improve this paper.

\section{References}

Baars, J. 1997 'Concepts of Time and Narrative Temporality in the Study of Aging', Journal of Aging Studies 11(4): 283-95.

Bergson, H. 1988 Matterand Memory, Brooklyn, NY: Zone Books [first published Paris: Presses Universitaires de France, 1908].

Binkley, S. 2009 'Governmentality, Temporality and Practice: From the Individual ization of Risk to the "Contradictory movements of the soul"', Time \& Society 18(1): 86-105.

Black, A. and Crann, M. 2002 'In the Public Eye: A Mass Observation of the Public Library', Journal of Librarianship and Information Science 34(3): 145-57.

Brockmeier, J. 1995 'The Language of Human Temporality: Narrative Schemes and Cultural Meanings of Time', Mind, Culture, and Activity 2(2): 102-18. 
Brockmeier, J. 2000 'Autobiographical Time', Narrative Inquiry 10(1): 51-73.

Bruner, J. 1995 'The Autobiographical Process', Current Sociology 43(2): 161-77.

Buffel, T., Phillipson, C. and Scharf, T. 2013 ‘Experiences of Neighbourhood Exclusion and Inclusion Among Older People Living in Deprived Innercity Areas in Belgium and England', Ageing and Society 33(1): 89-109.

Byrne, B. 2006 White Lives: The Interplay of 'Race', Class and Gender in Everyday Life, London: Routledge.

Bytheway, B. 2005 'Age-identities and the celebration of birthdays', Ageing \& Society 25(4): 463477.

Bönisch-Brednich, B. and Trundle, C. (eds) 2010 Local Lives: Migration and the Politics of Place, Farnham: Ashgate.

Carmo, R.M., Cantante, F. and de Almeida Alves, N. 2014 'Time Projections: Youth and Precarious Employment', Time \& Society 23(3): 337-57.

Coleman, R. 2008 “"Things That Stay": Feminist Theory, Duration and the Future', Time \& Society 17(1): 85-102.

de Medeiros, K. 2005 'The Complementary Self: Multiple Perspectives on the Aging Person', Journal of Aging Studies 19: 1-13.

Facchini, C. and Rampazi, M. 2009 'No Longer Young, Not Yet old: Biographical Uncertainty in LateAdult Temporality', Time \& Society 18(2/3): 351-72.

Fortier, A.-M. 2000 Migrant Belongings: Memory, Space, Identity, Oxford: Berg.

Frank, A.W. 1995 The Wounded Storyteller: Body, Illness and Ethics, Chicago, IL: University of Chicago Press. 
Hyman, L. 2014 'Happiness and Memory: Some Sociological Reflections', Sociological Research Online 19(2): 3, http://www.socresonline.org.uk/19/2/3.html

Luhmann, N. 1976 'The Future Cannot Begin:Temporal Structures in Modern Society', Social Research 43(1): 130-52.

May, V. 2001 Lone Motherhood in Finnish Women's Life Stories: Creating Meaning in a Narrative Context, Åbo: Åbo Akademi UniversityPress.

May, V. 2008 'On Being a “Good” Mother: The Moral Presentation of Self in Written Life Stories', Sociology 42(3): 470-86.

May, V. 2011 'Self, Belonging and Social Change', Sociology 45(3): 363-78.

May, V. 2013 Connecting Self to Society: Belonging in a Changing World, Basingstoke: Palgrave Macmillan.

May, V. 2016a 'What does the duration of belonging tell us about the self?', OnlineFirst Time \& Society DOI:10.1177/0961463X16656853.

May, V. 2016b 'Belonging from afar: Nostalgia, time and memory', Sociological Review Early View DOI: 10.1111/1467-954X.12402.

May, V. and Muir, S. 2015 'Everyday Belonging and Ageing: Place and Generational Change’, Sociological Research Online 20(1): 8, http://www.socresonline.org.uk/20/1/8.html

Mead, G.H. 1932 The Philosophy of the Present, Chicago, IL: University of Chicago Press.

Mellor, P.A. and Shilling, C. 1993 'Modernity, Self-Identity and the Sequestration of Death', Sociology 27(3): 411-31.

Morson, G.S. 1994 Narrative and Freedom: The Shadows of Time, New Haven, CT:Yale University Press. 
Muldoon, M.S. 2006 Tricks of Time: Bergson, Merleau-Ponty and Ricoeur in Search of Time, Self and Meaning, Pittsburgh, PA: Duquesne University Press.

Neugarten, B.L., Moore, J.W. and Lowe, J.C. 1965 `Age Norms, Age Constraints, and Adult Socialization', American Journal of Sociology 70(6): 710-17.

Passerini, L., Lyon, D., Capussotti, E. and Laliotou, I. (eds) 2007 Women Migrants from East to West: Gender, Mobility and Belonging in Contemporary Europe, Oxford: Berghan Books.

Pedersen, A.R. 2009 'Moving Away from Chronological Time: Introducing the Shadows of Time and Chronotopes as New Understandings of “Narrative Time"', Organization 16(3): 389-406.

Phoenix, C. and Sparkes, A.C. 2008 'Athletic Bodies and Aging in Context: The Narrative Construction of Experienced and Anticipated Selves in Time', Journal of Aging Studies 22: 211-21.

Probyn, E. 1996 Outside Belongings, New York: Routledge.

Ricoeur, P. 1984 Time and Narrative, Volume 1, Chicago, IL: University of Chicago Press [first published Paris: Editions de Seuil, 1983].

Roberts, B. 2004 'Health Narratives, Time Perspectives and Self-Images', Social Theory \& Health 2: 170-83.

Savage, M., Bagnall, G. and Longhurst, B. 2005 Globalization and Belonging: The Suburbanization of Identity, London: Sage.

Schatzki, T.R. 2010 The Timespace of Human Activity: On Performance, Society, and History as Indeterminate Teleological Events, Lanham, MD: Lexington Books.

Segal, L. 2013 Out of Time: The Pleasures and Perils of Ageing, London:Verso.

Sparkes, A.C. and Smith, B. 2003 'Men, Sport, Spinal Cord Injury and Narrative Time', Qualitative Research 3(3): 295-320. 
Spector-Mersel, G. 2006 ‘Never-Aging Stories: Western Hegemonic Masculinity Scripts’, Journal of Gender Studies 15(1): 67-82.

Uprichard, E. 2011 'Narratives of the Future: Complexity, Time and Temporality' in Williams, M. and Vogt, P. (eds) Handbook of Methodological Innovations in the Social Sciences, London: Sage.

Westerhof, G.J. 2010 “"During My Life So Much Has Changed That It Looks Like a New World to Me”: A Narrative Perspective on Migrating in Time', Journal of Aging Studies 24: 12-19.

Øian, H. 2004 'Time Out and Drop Out: On the Relation Between Linear Time and Individualis', Time \& Society 13(2/3): 173-95.

\footnotetext{
${ }^{1}$ Each MOP writer is given a unique identifier, consisting of a letter and number combination. I also indicate the gender of the writer ( $\mathrm{M}$ for male, $\mathrm{F}$ for female), followed by age and occupation if these are known. Place names and some specific details relating to occupation have been omitted to protect the anonymity of the writers. All extracts are true to the original, typographical and grammatical errors included (which I do not draw to the reader's attention).
} 